\title{
Good brace compliance reduced curve progression and surgical rates in patients with idiopathic scoliosis
}

\author{
Jens Ivar Brox $\cdot$ Johan Emil Lange • \\ Ragnhild Beate Gunderson · Harald Steen
}

Received: 30 January 2012/Revised: 8 May 2012/Accepted: 22 May 2012/Published online: 4 June 2012

(C) Springer-Verlag 2012

\begin{abstract}
Purpose To examine the association between brace compliance and outcome.

Patients and methods 495 (457 females) patients with late onset juvenile and adolescent idiopathic scoliosis were examined prospectively before bracing and at least 2 years after brace weaning. One spine surgeon examined all patients. 381 (353 females) answered a standardised questionnaire and 355 had radiological examination after median 24 years. Compliance was defined as brace wear $>20 \mathrm{~h}$ daily until weaning. Main outcomes were curve progression and surgery.

Results At weaning, 76/389 compliers and 59/106 noncompliers had curve progression $\geq 6^{\circ}$ (OR 5.2, $95 \%$ CI 3.3-8.2). At long-term the numbers were 68/284 and 46/71 (OR 5.8, $95 \%$ CI 3.3-10.2), 10/284 versus 17/71 had been operated (OR 8.6, $95 \%$ CI 3.7-19.9).

Conclusion We conclude that the risk for curve progression and surgery are reduced in patients with good brace compliance.
\end{abstract}

Keywords Idiopathic scoliosis - Bracing - Compliance . Curve progression · Surgery

J. I. Brox $(\bowtie)$ · J. E. Lange

Section for Back Surgery, Orthopaedic Department,

Rikshospitalet, Oslo University Hospital, Sognsvannsveien, 0027 Oslo, Norway

e-mail: jens.ivar.brox@rikshospitalet.no

R. B. Gunderson

Radiological Department, Rikshospitalet, Oslo University

Hospital, Sognsvannsveien, 0027 Oslo, Norway

H. Steen

Biomechanics Lab, Orthopaedic Department, Rikshospitalet, Oslo University Hospital, Sognsvannsveien, 0027 Oslo, Norway

\section{Introduction}

Idiopathic scoliosis is a structural lateral and rotary curvature of the spine in an otherwise normal child. It is reported that $0.3-0.5 \%$ of children younger than 16 years of age have a curvature $>20^{\circ}$ [21]. Recently, we reported that the point prevalence in 12-year-old children is $0.13 \%$ [2]. Long-term follow-ups indicate that health-related quality of life (HRQL), including pain, disability, work, and the number of children born in patients with curves ranging from $20^{\circ}$ to $50^{\circ}$, are comparable in patients with idiopathic scoliosis and the normal population [3, 10, 11]. A recently published Cochrane Review concluded that there is low evidence from well-designed scientific studies to support the use of braces to treat scoliosis [15]. In a prospective study, Nachemson and Peterson [14] showed that bracing alters the natural history of adolescent idiopathic scoliosis in the short term, but its efficacy in the long term has remained controversial. A recently published meta-analysis including mainly longitudinal cohort studies, reported that the percentage of brace-treated patients with later surgery ranges from 1 to $43 \%$ as compared with 13 to $28 \%$ after observation [5]. The meta-analysis has methodological limitations including poor documentation of compliance of brace wear and varying indications for surgery.

Recent studies suggest that the efficacy of bracing in terms of reduction of curve progression and the number of patients operated is good in compliant patients [17, 18]. One of the studies applied a sensor to the brace in order to reliably estimate hours of brace wear and reported that curve progression was reduced in compliant patients defined as brace wear $>20 \mathrm{~h}$ daily [17]. Thus, the weak evidence of the effectiveness of bracing may partly be explained by poor compliance. 
The aim of the present study was to prospectively evaluate the association between compliance of brace wear and progression of the scoliotic curve including the surgical rate in patients with idiopathic scoliosis treated with Boston brace. The secondary aim was to compare HRQL at long-term in compliant and non-compliant patients using both validated scoliosis-specific questionnaires and generic questionnaires.

\section{Materials and methods}

\section{Patients}

618 patients with scoliosis were treated from 1976 to 1988 with Boston brace at Sophies Minde Hospital (Orthopaedic Department, Rikshospitalet University Hospital) in Oslo, Norway. Due to various reasons [infantile idiopathic scoliosis $(n=15)$, syndrome scoliosis $(n=21)$, congenital scoliosis $(n=21)$, start of brace treatment later than 2 years after menarche $(n=24)$, brace treatment time less than 6 months $(n=10)$, dead $(n=12)$, miscellaneous (e.g. unknown address, moved to foreign country, etc.; $n=20)$ ] a total of 123 patients were excluded. Finally 495 (457 females) patients with juvenile or adolescent idiopathic scoliosis were invited to long-term follow-up. Health-related quality of life and curve progression at longterm have been published in 109 patients who had their last follow-up no longer than 2 years after brace weaning, and in 272 patients who had their last follow-up $>2$ years after brace weaning $[10,11]$.

The Ethical Committee for Medical Research in Health Region South-East of Norway and the hospital patient ombudsman approved the study.

\section{Bracing}

The indication for bracing was a major scoliotic curve $>20^{\circ}$ with an observed progression $>5^{\circ}$ after 4 months and skeletal immaturity evaluated by Risser sign $<3$ or bone age. Prior to bracing, standing radiographs were taken in the front and lateral projections. Patients were followed with clinical and radiological examination at 4-months intervals throughout the brace treatment period. A team comprising the spine surgeon (JEL), an experienced orthotist, and a nurse were responsible for brace fit and informing the young patient and parents about brace wear. Patients did not have regular physiotherapy, but were advised to participate in sports and ordinary physical activity at school. Ordinary brace treatment was continued until skeletal maturity, usually 2 years after menarche or until Risser 4 or 5 . After brace weaning all patients had follow-up at 6,12 , and 24 months. The majority of patients had one or more additional follow-up examinations before the long-term follow-up.

Primary outcome

The primary outcomes were compliance, curve progression, and surgery.

\section{Compliance}

Patients were recommended to use the brace for $23 \mathrm{~h}$ daily. Wearing of the brace was assessed by one orthopaedic surgeon (JEL) and scored on a standardised form. Scoring was based upon questioning the patient and the parents including the following questions: "Have the brace been used as prescribed? If not, do you use the brace at all? For how many hours weekly or daily are you not using the brace?"

Wearing of the brace $<20 \mathrm{~h}$ daily was noted as irregular. Compliance was reported as: used as prescribed, irregular, or aborted. Finally, compliance was dichotomised and patients were classified as compliant if the brace was used $>20 \mathrm{~h}$ daily until weaning.

\section{Radiology}

A standardised form was used to obtain clinical and radiological data. Radiological measurements were performed by an orthopaedic surgeon (JEL) and controlled by an experienced radiologist (RBG); both used the Cobb method manually. Digital measurements were used at longterm follow-up and the experienced radiologist controlled all measurements. The intra-observer error for the Cobb angle was about $3^{\circ}$ in a recent study using manual and digital measurements, and $<5^{\circ}$ in a previous study $[9,12]$. In the present study, the measurement error was within these limits as evaluated by the reproducibility of radiographic readings of repeated measurements of all radiographs from 10 patients at regular intervals. In patients with double-curved scoliosis, the largest curve prior to bracing was defined as the major curve. We calculated the number who had progressed according to the criteria by Nachemson and Peterson [16]. They defined success of treatment as a progression of the primary curve of $<6^{\circ}$ from the start of bracing. The patients who had surgery were classified as non-success.

\section{Surgery}

Surgery was recommended in immature patients with curve progression to $>45^{\circ}$ at follow-up during bracing or at weaning and $>50^{\circ}$ during later follow-ups. Information about surgery was recorded in the standardised form and 
obtained from the long-term questionnaire and crosschecked in the medical journals.

Secondary outcome

\section{Questionnaire}

At long-term follow-up a standardised questionnaire was filled in by all patients. It comprised validated measures of pain, disability, quality of life and work, comorbidity, surgery, and questions about demographics.

The Scoliosis Research Society 22 questionnaire (SRS-22) is widely used for the evaluation of HRQL in patients with idiopathic scoliosis and a validated Norwegian version was used in the present study [1]. The SRS-22 covers four domains (function/activity, pain, self-perceived image, and mental health) each with five questions, and one domain (satisfaction with treatment) with two questions. Each item has five verbal response alternatives ranging from 1 (worst) to 5 (best). Results are expressed as the mean (total sum of the domain divided by the number of items answered) for each domain.

Patients rated their overall function by the Global Back Disability Question [8]. This is a single question designed to measure the patients' overall rating of their back disability today. There were five response alternatives: "excellent, none or unimportant complaints," "good, occasionally bothered by back pain," "fair, some back pain and limited function," "poor, unchanged, considerable complaints and severe disability," and "miserable, worse, not self-reliant in activities of daily living".

A Norwegian version of the original Oswestry Disability Index (version 1.0) was used to evaluate back-specific disability [8]. The sum of 10 questions is calculated and presented as a percentage, wherein $0 \%$ represents no pain and disability, and $100 \%$ represents the worst pain and disability.

The General Function Score was used to measure disability in activities of daily living [6]. Patients answered nine questions using one of three alternatives: "can perform", "can perform with difficulty due to back complaints" and "cannot perform due to back complaints". The score was presented as a percentage wherein $100 \%$ represents maximum disability.

EuroQol is a generic (non-disease specific) questionnaire for measurement of HRQL and includes five items regarding quality of daily life, covering the domains of mobility, self-care, usual activities, pain and discomfort, and anxiety and depression (EQ-5D) and a visual analogue score for assessment of overall current health (EQ-VAS) $[1,20]$.

Evaluation of work status included questions about paid work (full-time, part-time, and not working) and status if not working (on sick leave, vocational or medical rehabilitation, disability pension, unemployed, homemaker, or student) [8].

\section{Statistical analysis}

Results are presented as means (standard deviation, range), numbers or percentages. The normal distribution of baseline, follow-up data, and differences were checked by histograms. A General Linear Model One-way analysis of variance was used to test differences in continuous variables at baseline, weaning, and long-term. Chi-square analyses were applied for testing of categorical variables. Odds ratio (95\% confidence interval) was used to describe the risk for curve progression and surgery in compliers and non-compliers. Adjustment for multiple tests was made by Bonferroni correction, the $P$ value was divided by the number of tests performed. Statistical analyses were performed with SPSS software, version 18.0 (SPSS Inc., Chicago) and Statistical Analysis System (SAS version 9.2; Cary, NC).

\section{Results}

$389(79 \%)$ patients were registered as compliant, 106 as non-compliant (54 irregular users and 52 aborted bracing). The reasons for non-compliance were psychological $(n=30)$, pain $(n=24)$, skin problems $(n=12)$, and unknown $(n=40)$.

Baseline characteristics except for gender were not different between compliers and non-compliers (Table 1). There were significantly $(P=0.017)$ more boys among non-compliers $(13 \%)$ than among compliers (6\%). Age and bone age at brace weaning and the major curve at weaning at 1 and 2 years were significantly $(P<0.001)$ different in compliers compared with non-compliers.

At weaning 76/389 compliers and 59/106 non-compliers had curve progression $\geq 6^{\circ}$ (OR 5.2, $95 \%$ CI 3.3-8.2) (Table 2). The number of patients who had surgery after weaning were $11 / 389$ and 22/106, respectively (OR 9.0, $95 \%$ CI 4.2-19.3).

The median time to long-term follow-up was 24 years (range 10-32 years). The mean time was 23.5 (4.0) years. Baseline characteristics and results at weaning and at 1- and 2-year follow-ups were similar in 381 (77\%) patients who attended, compared with 114 patients who did not attend (Table 3). Long-term radiological evaluation was performed in 355 (93\%) of these patients. At longterm 68/284 compliers and 46/71 non-compliers had curve progression $\geq 6^{\circ}$ (OR 5.8, $95 \%$ CI 3.3-10.2) and of these $10 / 284$ and $17 / 71$ had surgery (OR 8.6, $95 \%$ CI 3.7-19.9) (Table 4). $62 \%$ of patients with irregular use and $69 \%$ of 
Table 1 Characteristics according to compliance at baseline and short-term followup in 495 Boston-braced patients

Mean (SD) and years are given unless stated otherwise

${ }^{\text {a }} n=350$ and 87

${ }^{\mathrm{b}} n=200$ and 57

${ }^{c} n=375$ and 97

${ }^{\mathrm{d}} n=355$ and 82

e $n=11$ and 22

Table 2 Major curve progression $\geq 6^{\circ}$ at brace weaning and surgery after weaning in 495 Boston-braced patients

\begin{tabular}{lllll}
\hline Characteristic & $\begin{array}{l}\text { Compliers } \\
(n=389)\end{array}$ & $\begin{array}{l}\text { Non- } \\
\text { compliers } \\
(n=106)\end{array}$ & $\begin{array}{l}\text { OR } \\
(95 \% \mathrm{CI})\end{array}$ & $P$ \\
\hline $\begin{array}{l}\text { Curve } \\
\text { progression } \geq 6^{\circ \mathrm{a}}\end{array}$ & 76 & 59 & $5.2(3.3-8.2)$ & $<0.001$ \\
$\begin{array}{l}\text { Surgery } \\
\text { ung }\end{array}$ & 11 & 22 & $9.0(4.2-19.3)$ & $<0.001$
\end{tabular}

Numbers of patients and odds ratio (OR) with $95 \%$ confidence interval (CI) are given

${ }^{a}$ All patients who had surgery are counted with curve progression $\geq 6^{\circ}$ at weaning

those who aborted had curve progression $\geq 6^{\circ}$, while 26 and $22 \%$, respectively had surgery (Fig. 1). The longitudinal curve development in patients who had long-term radiological evaluation is shown in Fig. 2.

Compliers and non-compliers were comparable in most characteristics at long-term, but after correction for multiple statistical testing non-compliers were significantly more often smoking and compliers were more often married/living together (Table 5).
There were generally small differences in HRQL in favour of the compliers (Table 6). After correction for multiple testing, only self-image and SRS-22 scores for self-image and satisfaction with treatment were significantly better in compliant patients.

\section{Discussion}

The main finding in the present study is that the compliers had less curve progression and lower risk for surgery than non-compliers. The results indicate that bracing for $>20 \mathrm{~h}$ daily may alter the natural history in patients with idiopathic scoliosis.

A reliable method to assess compliance was not available when this study was started in 1976, which means that the validity of results may be questioned. In order to improve the evaluation of compliance, registration was standardised and performed by a single spine surgeon. Most likely the non-compliers were correctly identified, but an unknown number of those who are registered as compliant may also have used the brace for $<20 \mathrm{~h}$ daily. A study reported that compliance measured by a sensor was
Table 3 Characteristics at baseline and short-term followup in 381 Boston-braced patients who attended long-term follow-up and 114 who did not attend

Mean (SD) and years or degrees are given

${ }^{\text {a }} n=338$ and 99

b $n=202$ and 55

${ }^{c} n=363$ and 109

${ }^{\mathrm{d}} n=338$ and 99

e $n=27$ and 6

\begin{tabular}{llll}
\hline Characteristic & Attended $(n=381)$ & Did not attend $(n=114)$ & $P$ \\
\hline Gender, percentage males & 7 & 9 & 0.79 \\
Age at start brace treatment & $13.2(1.9)$ & $13.0(2.2)$ & 0.32 \\
Bone age at brace initiation & $12.6(1.9)$ & $12.4(2.3)$ & 0.43 \\
Age at menarche & $13.4(1.2)$ & $13.3(1.3)$ & 0.34 \\
Age at weaning & $15.9(1.4)$ & $15.6(1.6)$ & 0.09 \\
Bone age at weaning & b & $15.0(1.7)$ & 0.15 \\
Major curve at brace initiation $\left(^{\circ}\right)$ & $33.1(7.2)$ & $33.0(7.7)$ & 0.91 \\
Major curve at weaning $\left(^{\circ}\right)$ & $28.4(10.2)$ & $26.6(10.0)$ & 0.09 \\
Major curve at 1 year $\left({ }^{\circ}\right)^{\mathrm{c}}$ & $28.9(9.7)$ & $27.6(9.9)$ & 0.18 \\
Major curve at 2 years $\left({ }^{\circ}\right)^{\mathrm{d}}$ & $29.4(9.9)$ & $27.8(9.6)$ & 0.16 \\
Age at operation $(\text { years })^{\mathrm{e}}$ & $16.3(3.5)$ & $16.1(1.4)$ & 0.88 \\
\hline
\end{tabular}


Table 4 Major curve progression $\geq 6^{\circ}$ and surgery in 355 (of 381) Boston-braced patients at long-term follow-up

\begin{tabular}{lllll}
\hline Characteristic & $\begin{array}{l}\text { Compliers } \\
(n=284)\end{array}$ & $\begin{array}{l}\text { Non- } \\
\text { compliers } \\
(n=71)\end{array}$ & $\begin{array}{l}\text { OR } \\
(95 \% \mathrm{CI})\end{array}$ & $P$ \\
\hline $\begin{array}{l}\text { Curve } \\
\text { progression } \geq 6^{\text {oa }}\end{array}$ & 68 & 46 & $5.8(3.3-10.2)$ & $<0.001$ \\
$\begin{array}{l}\text { Surgery } \\
\text { ung }\end{array}$ & 10 & 17 & $8.6(3.7-19.9)$ & $<0.001$ \\
\hline
\end{tabular}

Numbers of patients and odds ratio (OR) with $95 \%$ confidence interval (CI) are given

${ }^{a}$ All patients who had surgery are counted with curve progression $\geq 6^{\circ}$

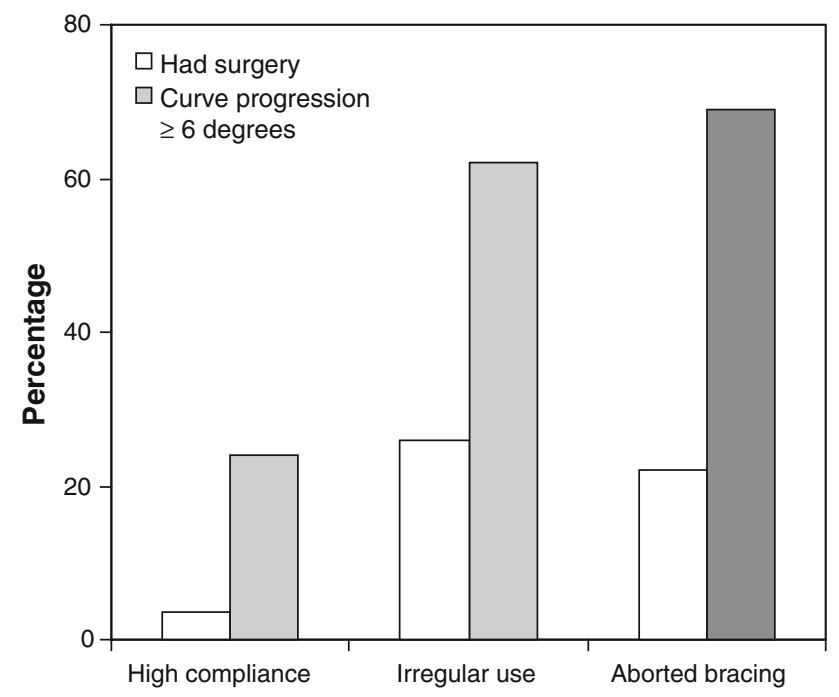

Fig. 1 The percentages of patients with high compliance $(3.5 \%)$, irregular use $(26 \%)$, and aborted bracing $(22 \%)$ with surgery, and the percentages $\left(24,62\right.$, and $69 \%$ ) with curve progression $\geq 6^{\circ}$, respectively, at long-term follow-up, are shown

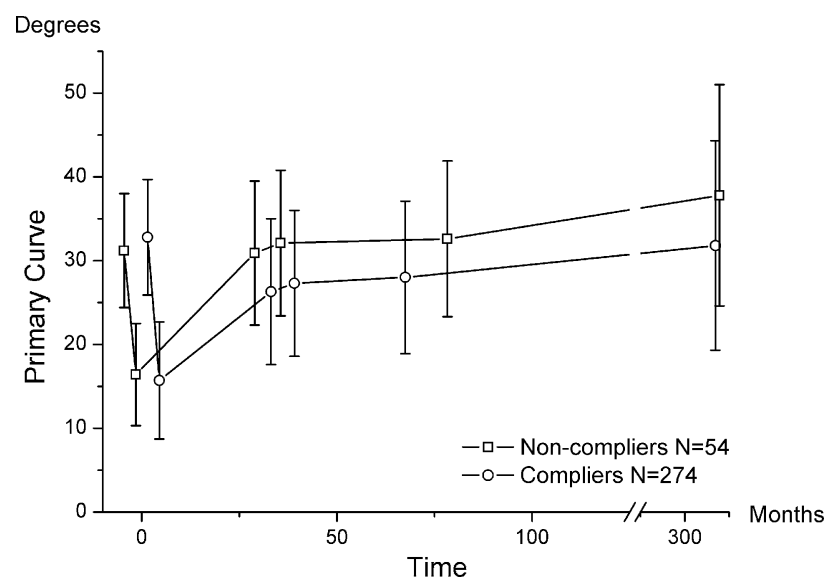

Fig. 2 Development of the major scoliotic curve is shown in 328 patients with long-term radiological evaluation. Operated patients $(n=27)$ are not included. Mean Cobb angle \pm 1 SD prebrace, at brace weaning, at 1- and 2-year, and at long-term follow-up are shown in 274 compliant patients and 54 non-compliant patients
$75 \%$ of the hours prescribed by the regimen as compared to $85 \%$ reported by the patients [19].

Strengths of the present study include the standardised follow-up of patients by one experienced spine surgeon and experienced orthotists, who adapted the braces individually; the large study sample; the high follow-up rate; longterm follow-up; radiological evaluation; and the use of validated questionnaires for evaluation of HRQL at longterm follow-up.

We evaluated the efficacy of bracing and results are in agreement with one study using an objective electronic monitor to estimate the time in brace in 34 patients [17]. They reported curve progression in $11 \%$ with high compliance and $56 \%$ with low compliance as compared to 24 and $65 \%$ in the present study at long-term. Inclusion criteria and the prescribed brace regimens seem quite similar in the two studies, but the former study applied the Wilmington brace, while patients in the present study used the Boston brace. A study of long-term results after Boston brace not using a monitor, reported curve progression in $23 \%$ of compliant patients and $33 \%$ of non-compliant patients [26].

Seifert et al. [18] evaluated compliance in 90 patients with adolescent idiopathic scoliosis applying Dresden scoliotic orthosis. $59 \%$ was considered to use the brace $>20 \mathrm{~h}$ daily and was defined as compliant. $28 \%$ in the non-compliant group and $7 \%$ in the compliant group underwent surgery as compared to 21 and $3 \%$ in the present study. The success rate according to curve progression was comparable to the present study.

It is demanding for an adolescent girl or boy to wear a rigid brace $20 \mathrm{~h}$ or more daily for 2-3 years. The enthusiasm and skills of the treating team including the spine surgeon and the orthotist; brace initiation time; different types/design of the brace; and the motivation of the patients and their parents may contribute to compliance. The results of the present study suggest that these factors were considered, nevertheless patients in both groups scored lower on satisfaction with treatment than any other of the HRQL domains at long-term follow-up. We did not assess physical activity, but a recent study using objective measures of physical activity (step activity monitoring) and of compliance (core probe) indicates that brace treatment do not interfere with physical activity [13]. This is an important finding that can be provided to patients and parents in order to reduce worries concerning bracing. Interestingly, in accordance with the present study, it was also reported that there was a tendency for better compliance in girls compared with boys.

Night-time bracing and flexible spinal orthosis have been introduced in order to improve compliance. One study reported that curve progression at short-time follow-up was not different in patients using the Providence night-time 
Table 5 Socio-demographic characteristics in 381 Bostonbraced patients at long-term follow-up
Percentages are given, except that mean (SD) number of children are reported

After Bonferroni correction for multiple testing (nine tests), $P$ values $<0.006$ are considered significant

Table 6 Health-related quality of life in 381 Boston-braced patients at long-term follow-up

Mean (SD) are given unless stated otherwise

After Bonferroni correction for multiple testing (10 tests),

$P$ values $<0.005$ are considered significant

\begin{tabular}{|c|c|c|c|}
\hline Characteristic & Compliers $(n=305)$ & Non-compliers $(n=76)$ & $P$ \\
\hline \multicolumn{4}{|l|}{ Educational level } \\
\hline Primary school ( 9 year) & 9 & 7 & \multirow[t]{3}{*}{0.39} \\
\hline High school (12 year) & 20 & 32 & \\
\hline University college & 71 & 62 & \\
\hline \multicolumn{4}{|l|}{ Work status } \\
\hline Working full time & 79 & 71 & \multirow[t]{7}{*}{0.35} \\
\hline Working part-time & 8 & 12 & \\
\hline Student & 1 & 2 & \\
\hline Homemaker & 3 & 3 & \\
\hline On sick leave & 3 & 2 & \\
\hline Rehabilitation & 2 & 2 & \\
\hline Disability pension & 4 & 8 & \\
\hline $\begin{array}{l}\text { Changed job because of back pain } \\
\text { or disability }\end{array}$ & 23 & 31 & 0.30 \\
\hline $\begin{array}{l}\text { Scoliosis influenced my choice } \\
\text { of education and job }\end{array}$ & 26 & 40 & 0.02 \\
\hline Comorbidity & 32 & 31 & 0.94 \\
\hline Smoking & 17 & 35 & 0.001 \\
\hline Married/living together & 83 & 65 & 0.002 \\
\hline Born children $(n=353)$ & 85 & 89 & 0.55 \\
\hline Pain in pregnancy $(n=305)$ & 52 & 49 & 0.77 \\
\hline Mean number of children $(n=351)$ & $1.8(1.1)$ & $1.9(1.0)$ & 0.67 \\
\hline
\end{tabular}

\begin{tabular}{llll}
\hline Outcome & Compliers $(n=305)$ & Non-compliers $(n=76)$ & $P$ \\
\hline Global Back Disability Question $(n)$ & & & 0.11 \\
Excellent & 91 & 13 & \\
Good & 131 & 41 & \\
Fair & 70 & 16 & \\
Poor & 13 & 6 & 0.20 \\
General Function Score (0-100) & $6.5(11.4)$ & $8.5(12.3)$ & 0.01 \\
Oswestry Disability Index (0-100) & $7.7(11.8)$ & $11.8(13.1)$ & 0.01 \\
EQ-5D (-0.5 to 1.0) & $0.83(0.20)$ & $0.75(0.24)$ & 0.11 \\
EQ-VAS (0-100) & $78.7(17.4)$ & $74.7(19.2)$ & \\
SRS-22 (1-5) & & & 0.04 \\
Pain & $4.1(0.8)$ & $3.9(0.9)$ & 0.06 \\
Physical function & $4.1(0.6)$ & $4.0(0.7)$ & 0.04 \\
Mental health & $4.2(0.6)$ & $4.0(0.7)$ & 0.003 \\
Self-image & $3.8(0.7)$ & $3.5(0.7)$ & $<0.001$ \\
Satisfaction & $3.8(1.0)$ & $3.3(1.0)$ & \\
\hline
\end{tabular}

brace and the Boston full-time brace, but compliance was not assessed [25]. A prospective study reported curve progression in $32 \%$ of the patients using a flexible brace versus in $5 \%$ of the patients using a rigid brace [23]. Patients' acceptance was not different. Another prospective study comparing two different braces reported that the scoliosis progressed in the majority of patients using a flexible brace [22]. A recent small cohort study reported
$54 \%$ compliance of the recommended $24 \mathrm{~h}$ and suggested that compliance was not improved by the use of dynamic braces [7].

$\mathrm{Xu}$ et al. [24] reported in a current study that genes for oestrogen receptor $\alpha$ and tryptophan might be potential genetic predictors for the outcome of brace treatment. In a study including 219 AIS patients at 1-year follow-up, maturity (Risser sign 0 and 1), but not curve size, predicted 
curve progression in addition to the candidate genes. Patients with $<75 \%$ compliance were excluded. Future prospective studies should assess the influence of candidate genes, compliance and maturity on long-term curve progression in brace-treated patients.

The ideal study design to evaluate the comparative effectiveness of bracing is the randomised controlled trial and the results of two ongoing trials are awaited [4, 21]. However, it is important not to limit the evaluation to comparative effectiveness, which relates to the differences in patients randomised to brace wear or no brace. Also the efficacy of bracing per se, which is a comparison of compliant and non-compliant patients, is important, because in clinical practice there are several obstacles to proper bracing.

We conclude that good brace compliance reduced curve progression and the rate of surgery in patients with juvenile and adolescent idiopathic scoliosis.

Acknowledgments We would like to thank the orthotists, nurses, and patients who made this study possible. We would also like to thank Tonje Midtsveen for coordinating patients at long-term, Julia Brox Skranes and Johanne Brox Skranes for punching the data, Per Lundvigsen for making the figures, and Raphael Adobor for comments on the draft of the paper. The study was supported by grants from the Foundation Sophies Minde Ortopedi AS.

Conflict of interest None.

\section{References}

1. Adobor RD, Rimeslåtten S, Keller A, Brox JI (2010) Repeatability, reliability, and concurrent validity of the scoliosis research society-22 questionnaire and EuroQol in patients with adolescent idiopathic scoliosis. Spine 35:206-209

2. Adobor RD, Rimeslåtten S, Steen H, Brox JI (2011) School screening and point prevalence of adolescent idiopathic scoliosis in 4000 Norwegian children aged 12 years. Scoliosis 6:23

3. Danielsson A, Nachemson AL (2001) Childbearing, curve progression, and sexual function in women 22 years after treatment for adolescent idiopathic scoliosis: a case-control study. Spine 26:1449-1456

4. de Koning HJ (2007) Effectiveness of bracing patients with adolescent idiopathic scoliosis. Nederlands Trial Register http:// www.trialregister.nl/trialreg/admin/rctview.asp

5. Dolan LA, Weinstein SL (2007) Surgical rates after observation and bracing for adolescent idiopathic scoliosis: an evidence-based review. Spine 32:S91-S100

6. Hägg O, Fritzell P, Romberg K, Nordwall A (2001) The General Function Score: a useful tool for measurement of physical disability. Validity and reliability. Eur Spine J 10:203-210

7. Hasler CC, Wietlisbach S, Buchler P (2010) Objective compliance of adolescent girls with idiopathic scoliosis in a dynamic SpineCor brace. J Child Orthop 4:211-218

8. Holm I, Friis A, Storheim K, Brox JI (2003) Measuring selfreported functional status and pain in patients with chronic low back pain by postal questionnaires. A reliability study. Spine 28:828-833
9. Kuklo TR, Potter BK, Schröder TM, O'Brien MF (2006) Comparison of manual and digital measurements in adolescent idiopathic scoliosis. Spine 31:1240-1246

10. Lange JE, Steen H, Brox JI (2009) Long-term results after Boston brace treatment in adolescent idiopathic scoliosis. Scoliosis 4:17

11. Lange JE, Steen H, Gunderson R, Brox JI (2011) Long-term results after Boston brace treatment in late-onset juvenile and adolescent idiopathic scoliosis. Scoliosis 6:18

12. Morrissy RT, Goldsmith GS, Hall EC, Kehl D, Cowie GH (1990) Measurement of the Cobb angle on radiographs of patients who have scoliosis. Evaluation of intrinsic error. J Bone Joint Surg Am 72:320-327

13. Müller C, Fuchs K, Winter C, Rosenbaum D, Schmidt C, Bullmann V, Schulte TL (2011) Prospective evaluation of physical activity in patients with idiopathic scoliosis or kyphosis receiving brace treatment. Eur Spine J20:1127-1136

14. Nachemson AL, Peterson LE (1995) Effectiveness of treatment with a brace in girls who have adolescent idiopathic scoliosis. A prospective, controlled study based on data from the Brace Study of the Scoliosis Research Society. J Bone Joint Surg Am 77:815822

15. Negrini S, Minozzi S, Bettany-Saltikov J, Zaina F, Chockalingam N, Grivas TB, Kotwicki T, Maruyama T, Romano M, Vasiliadis ES (2010) Braces for idiopathic scoliosis in adolescents. Cochrane Database of Systematic Reviews

16. Peterson LE, Nachemson AL (1995) Prediction of progression of the curve in girls who have adolescent idiopathic scoliosis of moderate severity. Logistic regression analysis based on data from The Brace Study of the Scoliosis Research Society. J Bone Joint Surg Am 77:823-827

17. Rahman T, Bowen JR, Takemitsu M, Scott C (2005) The association between brace compliance and outcome for patients with idiopathic scoliosis. J Pediatr Orthop 25:420-422

18. Seifert J, Selle A, Flieger C, Gunther KP (2009) Compliance as a prognostic factor in the treatment of idiopathic scoliosis. Orthopäde 38:151-158

19. Takemitsu M, Bowen JR, Rahman T, Glutting JJ, Scott CB (2004) Compliance monitoring of brace treatment for patients with idiopathic scoliosis. Spine 29:2070-2074

20. Tosteson ANA (2000) Preference-based health outcome measures in low back pain. Spine 25:3161-3166

21. Weinstein SL, Dolan LA (2007) BrAIST: the bracing in adolescent idiopathic scoliosis trial. US National Institute of Health http://www.clinicaltrials.gov/ct/show/NCT00448448

22. Weiss HR, Weiss GM (2005) Brace treatment during pubertal growth spurt in girls with idiopathic scoliosis (IS): a prospective trial comparing two different concepts. Pediatr Rehabil 8:199206

23. Wong MS, Cheng JCY, Lam TP, Ng BKW, Sin SW, Lee-Shum SLF, Chow DHK, Tam SYP (2008) The effect of rigid versus flexible spinal orthosis on the clinical efficacy and acceptance of the patients with adolescent idiopathic scoliosis. Spine 33:13601365

24. Xu LL, Qiu XS, Sun X, Mao SH, Liu Z, Qiao J, Qiu Y (2011) Potential genetic markers predicting the outcome of brace treatment in patients with adolescent idiopathic scoliosis. Europ Spine J 20:1757-1764

25. Yrjonen T, Ylikoski M, Schlenzka D, Kinnunen R, Poussa M (2006) Effectiveness of the Providence nighttime bracing in adolescent idiopathic scoliosis: a comparative study of 36 female patients. Europ Spine J 15:1139-1143

26. Yrjonen T, Ylikoski M, Schlenzka D, Poussa M (2007) Results of brace treatment of adolescent idiopathic scoliosis in boys compared with girls: a retrospective study of 102 patients treated with the Boston brace. Europ Spine J 16:393-397 